\title{
Protecting the future well: access to preconception genetic screening and testing and the right not to use it
}

\section{Isabel Ann Karpin}

To cite this article: Isabel Ann Karpin (2016) Protecting the future well: access to preconception genetic screening and testing and the right not to use it, Griffith Law Review, 25:1, 71-86, DOI: 10.1080/10383441.2016.1203274

To link to this article: http://dx.doi.org/10.1080/10383441.2016.1203274

\section{曲 Published online: 03 Jul 2016.}

Submit your article to this journal Article views: 4




\title{
Protecting the future well: access to preconception genetic screening and testing and the right not to use it
}

\author{
Isabel Ann Karpin (1) \\ Faculty of Law, University of Technology Sydney, Sydney, Australia
}

\begin{abstract}
In this article, I assess the ethical and legal implications for a progressive and inclusive approach towards people with disability, of providing publicly funded and universal access to carrier testing and expanded carrier testing. In answering this question I focus on two main concerns namely whether such access (1) involves a neoliberal individualisation of risk and responsibility away from the State and (2) might impinge on the reproductive and other rights of people with disability. With respect to this last question I ask specifically is it possible to provide whole-population preconception genetic carrier screening while legally guaranteeing the reproductive rights to conceive of prospective parents, both women and men, who test positive as a carrier for an inheritable genetic condition?
\end{abstract}

\section{KEYWORDS}

Disability; genetic carrier testing; reproductive rights

\section{Introduction}

A 'normal' genetic profile is determined as much by the social as the scientific context and can entrench existing assumptions about what it is to be healthy. Medical explanations of disease, for example, are inflected by gendered and raced assumptions that layer over or intersect with already contested accounts of what it is to be a person with disability. Genetic carrier screening is a form of genetic testing that enables a person to ascertain their risk of having a child with certain genetic conditions prior to conception. Expanded carrier testing is a new form of this technology that allows a person to check for hundreds of possible genetic mutations simultaneously, without incurring significantly greater cost. However, the kinds of genetic mutations that might make up the category of the normatively undesirable and be included in such tests are highly contested.

The national health care system in Australia is based on the broad principle of equal access to health services for all and the universal health cover system, Medicare, was introduced in 1984 to provide free or subsidised treatment by health professionals in certain specified areas. ${ }^{1}$ More recently, the National Healthcare Agreement 2015 formed between

\footnotetext{
CONTACT Isabel Ann Karpin $\otimes$ isabel.karpin@uts.edu.au

${ }^{1}$ Medicare usually covers: (i)"free or subsidised treatment by health professionals such as doctors, specialists, optometrists and in specific circumstances dentists and other allied health practitioners and accommodation as a public patient in a public hospital (ii) 75 per cent of the Medicare Schedule fee for services and procedures if you are a private patient in a public or private hospital (does not include hospital accommodation and items such as theatre fees and medicines) and (iii) some health-care services in certain countries: Department of Human Services, 'Australia's health 2014', http://www. aihw.gov.au/australias-health/2014/health-system/

(c) 2016 Griffith University
} 
the federal government and the states and territories affirmed four main principles, the fourth of which states that Australia's health system should 'provide all Australians with timely access to quality health services based on their needs, not ability to pay, regardless of where they live in the country'. Furthermore, among the objects of the agreement is the outcome that 'Australians are born and remain healthy'. ${ }^{2}$ On the assumption then, that equality of access to health care services is a key component of the Australian health care system, it is worth examining to what extent, if any, genetic carrier screening that provides individuals and couples with information about their risk of having a child with a genetic condition constitutes 'treatment' to which Medicare-funded access ought properly to be provided.

In this article, I assess the ethical and legal implications for a progressive and inclusive approach towards people with disability, of providing publicly funded and universal access to carrier testing and expanded carrier testing. In answering this question I focus on two main concerns namely whether such access (1) involves a neoliberal individualisation of risk and responsibility away from the State and (2) might impinge on the reproductive and other rights of people with disability. With respect to this last question I ask specifically is it possible to provide whole-population preconception genetic carrier screening while legally guaranteeing the reproductive rights to conceive of prospective parents, both women and men, who test positive as a carrier for an inheritable genetic condition?

\section{Standard genetic screening and the impact of new expanded carrier testing?}

Traditionally, genetic screening has been disease-based, concentrating on specific conditions that are known to be prevalent in particular ethnic backgrounds and generally conceded to be severely disabling or life-threatening. For example, screening programs for Tay Sachs Disease (TSD) (a condition that progressively destroys nerve cells and results in death in very early childhood) targeting Ashkenazi Jewish patients and similar programs for Sickle Cell Disease (a group of conditions that involves a red blood cell disorder that can result in severe pain and a shortened life span) targeting people of West African, African-Caribbean, Indian, Arabic and Mediterranean origin have resulted in race- and ethnicity-specific screening. While initially responding to the prevalence of a specific condition, these population-based ethnicity-specific programs demonstrate a tendency to rapidly expand to include additional conditions and tests. For example, in Australia, although TSD screening began just targeting TSD in 15-17-year-old students attending Jewish high schools in NSW in 1995 and in Melbourne in 1998, ${ }^{3}$ today those same populations are now targeted for genetic screening for a number of conditions that are described as having an increased frequency in Jewish populations: cystic fibrosis (CF), mucolipidosis-type VI, Fanconianaemia, familial dysautonomia, Canavan disease and Bloom Syndrome. ${ }^{4}$

\footnotetext{
${ }^{2}$ Australian Institute of Health and Welfare, 'National Healthcare Agreement (2015)', http://meteor.aihw.gov.au/content/ index.phtml/itemld/558998

${ }^{3}$ Lew et al (2015), p 20.

${ }^{4}$ Lew et al (2015), p 20. This upsizing has occurred where the DorYeshorim platform is used within orthodox communities in other countries as well. Notably Israel and the USA: see Inthorn (2014).
} 
Migration and inter-marriage have ensured that ethnic-specific categories (if they ever were reliable) have become less compelling as identifiers of potential disease inheritance. The development of expanded carrier testing has led some to argue that the racialisation or ethnicisation of risk should be replaced with a pan ethnic or universal approach to preconception screening targeting multiple diseases and genetic conditions across populations. This would avoid the concomitant risks of ethnic-specific testing that arise from inaccuracies of ancestral knowledge and an increasingly transglobal and multiethnic society. It would also go some way to tackling the stigmatising social consequences of identifying specific diseases with racial and ethnic minorities. For example, Maria Berghs et al argue that, while originally screening programs for sickle cell were 'socio-politically allied to ideas of repair, in terms of the state improving the health of a neglected ethnic minority population', 5 the assignation of Sickle cell as a 'black disease' led to carrier status being used to discriminate. They go on to observe that 'SCD is located within a system of stigmatised signs (being "black"), collective memory of racialised medicine and "black" reproductive politics predisposing it to a hermeneutics of suspicion. ${ }^{6}$

While a pan ethnic or universal approach to preconception screening that targets multiple genetically based diseases would potentially overcome concerns over racialisation of specific conditions, each condition tested raises different ethical issues that may be obscured by broad spectrum screening. In order to understand the ethical debate it is helpful to focus first on one condition before looking at the question of an expanded panel of conditions.

$\mathrm{CF}$ is the most common autosomal recessive disorder in the Caucasian population generally $^{7}$ and medical professional organisations hold inconsistent views on whether screening for CF should be offered to all preconceptual and prenatal patients - not just those identified as susceptible on the basis of ethnicity. In Australia, the Human Genetics Society of Australasia (HSGA) recommends that '[a]ll couples intending to have children, or who are pregnant, should be made aware of the availability of cystic fibrosis carrier screening. ${ }^{8}$ This recommendation is partly based on an assessment of the American College of Medical Genetics and Genomics (ACMG) and the American College of Obstetricians and Gynecologists (ACOG) recommendations. Their 2011 guidelines recommend that screening for CF be offered to all preconceptual and prenatal patients regardless of ethnic background on the basis that ' $\mathrm{i}] \mathrm{t}$ is becoming increasingly difficult to assign a single ethnicity to individuals'. ${ }^{9}$ In adopting a similar position the HGSA reviewed the published data and found there was minimal evidence of adverse psychosocial outcomes for women identified as carriers of CF in population-based screening programs. ${ }^{10}$ They also recommend either Two-step screening or Expanded one-step screening. In the case of the former, one member of the couple is tested first. If they are found to be a carrier then the partner is tested. Notably, in their Position Statement the HGSA states:

\footnotetext{
${ }^{5}$ Berghs et al (2015), p 11.

${ }^{6}$ Berghs et al (2015), p 11.

${ }^{7}$ Bajaj and Gross (2014), p 1034.

${ }^{8}$ Delatycki et al (2014), p 581.

${ }^{9}$ American College of Obstetricians and Gynecologists Committee on Genetics ACOG (2011), p 1030.

${ }^{10}$ Delatycki et al (2014), p 581.
} 
In this model one member of the couple (usually the female) is tested initially. If she is found to be a carrier then her partner is tested ... ${ }^{11}$

Women, perhaps inadvertently, appear to bear the brunt of the testing burden. The HGSA do indicate, however, that the preferred model is expanded one-step screening where both members of the couple are tested at once and given access to their test results individually. In Australia, CF is the most common genetically identifiable conditions affecting children with European backgrounds and in 90 per cent of cases of children born with the condition there is no existing family history. ${ }^{12}$

Should all Australians, regardless of ethnicity, contemplating having children be offered, as a matter of equality of access to health services, publicly funded preconceptual carrier testing for CF? First, the test for CF is only 84 per cent accurate, giving rise to a small percentage of false reassurances. In any panel test the accuracy rate for different conditions will vary. Secondly, CF presents with varying levels of severity so that a positive genetic test is a fairly crude measure of risk. The relevant threshold of severity may be difficult to ascertain and consequently, it will be questionable whether it is a condition that warrants screening or elimination. ${ }^{13}$ Presently, for people with no family history of CF, the test is available only on a user pays basis in Australia and the HGSA notes that this is a consideration when recommending 'that all couples should be made aware of the availability of CF carrier screening ... ${ }^{14}$ Publicly funded access, therefore, becomes a major impediment to giving effect to this recommendation.

\section{Publicly funded universal access to expanded carrier testing and the testing burden}

As already noted the availability of expanded carrier screening changes the ethical debate around 'universal' screening of singular disorders by making it possible to test for many conditions at one time. This inevitably raises concerns about what constitutes a disability, who determines what conditions are included in panel tests and when is it appropriate to offer such testing. Kumal Bajaj and Susan Gross note that '[e]xpanded panels have received criticism because some of the disorders selected may not be clinically significant, have an overall low frequency or a variable onset and clinical course'. ${ }^{15}$

The HSGA has not produced a position statement on expanded carrier testing but it is useful to consider the statement provided by the ACMG, together with the ACOG, the National Society of Genetic Counselors, the Perinatal Quality Foundation and the Society for Maternal-Fetal Medicine. These groups have issued a joint statement regarding the appropriate use of expanded carrier screening. ${ }^{16}$ Specifically, they note that '[e]xpanded panels screen for conditions with a wide range of severity and age of onset and frequently have carrier frequencies that are not known for all populations ${ }^{37}$ and therefore the

\footnotetext{
${ }^{11}$ Delatycki et al (2014), p 580.

${ }^{12}$ Modra et al (2010).

${ }^{13}$ See Karpin and Savell (2012) for a discussion of the controversy surrounding notions of seriousness in testing.

${ }^{14}$ Delatycki et al (2014), p 583.

${ }^{15}$ Bajaj and Gross (2014).

${ }^{16}$ Edwards et al (2015).

${ }^{17}$ Edwards et al (2015), p 6.
} 
conditions screened for should be limited to conditions where one or more of the following exist:

(1) Cognitive disability

(2) Need for surgical or medical intervention

(3) Effect on quality of life and

(4) conditions for which prenatal diagnosis might result in

(a) prenatal intervention to improve perinatal outcome and immediate care of the neonate.

(b) delivery management to optimise newborn and infant outcomes such as immediate, specialised neonatal care.

(c) Prenatal education of parents regarding special needs care after birth: this often may be accomplished most effectively before birth. ${ }^{18}$

However, the statement also suggests that it may be preferable not to screen for conditions in which:

(1) the disorder is associated most often with an adult-onset phenotype and molecular testing cannot distinguish between childhood or adult onset.

(2) variants have high allele frequencies and low penetrance of a phenotype.

(3) the most appropriate approach to screening is something other than molecular testing, often because of low penetrance when molecular variants are identified.

In other words testing is not recommended for conditions which are highly unlikely or where the disorder may only present in adulthood. While we have no Australian equivalent the HGSA has, however, indicated in its Position Statement on Population Based Carrier Screening for Cystic Fibrosis that expanded carrier testing is already available as direct to consumer testing and screens for several hundred mutations. It is noted there that though initially a low cost high fidelity option, expanded carrier testing nevertheless may result in greater costs over time because of the enlarged need for pre- and post-test counselling and follow-up testing. ${ }^{19}$

Based on these various professional organisation statements, it seems clear that the key ethical concern in expanded carrier screening is going to be which tests are included in the panel. Although not referring directly to 'seriousness', the American Colleges joint statement clearly recommends against testing for conditions that do not reach a threshold of seriousness. But, there is nothing in the statement that acknowledges the level of disagreement that exists among health practitioners and disability advocates over what conditions it is appropriate to include in a test. ${ }^{20}$ It has been argued that making a test available for a particular trait or condition works like a feedback loop, generating a conviction that the trait or condition being tested is one for which testing is needed. ${ }^{21}$ However, if the conditions included in the panel for testing are not seriously disabling or indeed their

\footnotetext{
${ }^{18}$ Edwards et al (2015).

${ }^{19}$ Delatycki et al (2014).

${ }^{20}$ For a small selection see: Asch (2003), Ettorre (2002) and Parens and Asch (2003).

${ }^{21}$ Lippman (1991) and Phelan et al (2013).
} 
classification is the subject of significant disagreement, the desire or 'need' to be tested is based on a false assumption. Potential parents who view the mere inclusion of the condition in the panel as a sign that it is sufficiently serious to warrant testing may feel compelled by an unjustifiable testing imperative. While this may not justify a legal prohibition on testing for these conditions, it may provide an ethical basis to exclude universal testing for those conditions.

The American Colleges' joint statement does, however, refer to the fact that testing for late-onset conditions is not recommended. Apart from the fact that there is significant ethical debate about whether prenatal including preimplantation genetic diagnosis (PGD) (let alone preconception) testing is appropriate for late-onset conditions ${ }^{22}$ which include genetic mutations as varied as Huntington's (with 100 per cent penetrance) and the Breast cancer genes BRCA 1 and 2 (with 85 per cent penetrance) in the case of preconception carrier screening the risk posed by universal testing is multiplied. Carrier testing is aimed to identify mutations in recessive genes with no phenotypic expression in the relevant individual. However, it is possible that in some cases the person may himself or herself be found to have the condition. In that case testing that initially aimed to identify carrier status may actually identify the presence of a late-onset condition, or a mild version of a condition about which the person was otherwise unaware. This makes the HGSA remarks that any universal testing scheme will need to be supported by comprehensive pre- and post-test counselling vital.

Thus when considering whether there is a case for public health provision of expanded carrier testing, it is important to weigh in the balance any increase in the testing burden, and the consequent possibility of stigma and discrimination that results from a positive test result. A regulatory system which favoured universal and publicly funded expanded carrier testing would be premised on a perceived assessment of risk and benefit to future possible children. However, this approach has the potential to shift the focus away from the health and well-being of existing persons, their privacy rights and their need for protection against disability (or imputed disability) based discrimination. ${ }^{23}$ Instead it may create abstract responsibilities towards those who do not yet exist and may never come to exist. ${ }^{24}$ Furthermore, as argued below, the testing burden tends to fall more heavily on women and this raises additional ethical concerns about the way in which these tests have a gendered impact.

\section{The individualisation of risk and responsibility for the welfare of future children}

The Royal Australian and New Zealand College of Gynaecologists and Obstetricians commented on the availability of expanded carrier testing in its guidelines on Prenatal screening and diagnosis of chromosomal and genetic abnormalities in the fetus in pregnancy.

\footnotetext{
${ }^{22}$ The National Health and Medical Council Ethical Guidelines on Assisted Reproduction in Clinical Practice and Research state in paragraph 12.2 that PGD should only be used for the prevention of conditions that seriously harm the person to be born. There is an open question about whether late onset conditions such as breast cancer would fall within that definition. Nevertheless there has been regulatory approval of PGD for BRCA in Victoria and WA and in NSW clinics have interpreted the paragraph as inclusive of BRCA testing. See Karpin and Savell (2012).

${ }^{23}$ Disability Discrimination Act 1992 (Cth).

${ }^{24}$ There has been significant philosophical debate about whether moral value can be attached to the action of avoiding the birth of a child with a disability. In her book Scott (2007) at p 39 provides a critical discussion of the work of Derek Parfit who has suggested that there is no harm where the alternative for a child who would be born with a disability is not to be born. If that child never comes to exist, then there is no person affected by the decision. This is the non-person affecting principle.
} 
Under the heading 'Population-based preconceptional genetic screening' it is noted that it may be more economical to take the two-step approach to screening. In this case the guidelines state: 'test the female first and then only test the male partner should she be found to be a carrier of the specific autosomal recessive condition(s) being screened for ${ }^{25}$ Scant attention is paid to the way these economic efficiencies increase the testing burden for women and its financial and psychological consequences.

As noted at the outset, recommendations that all couples should be made aware of the availability of certain screening tests, ${ }^{26}$ where funding for and access to those tests is not universally available, can result in unnecessary parental stress and anxiety if there is inability to privately purchase those services. An approach that focuses on merely ensuring awareness of the availability of a test has the effect of shifting the burden of responsibility for future good health and well-being away from the State to individuals. Preconception health and awareness programs developed by government health departments and implemented by general practitioners, where unsupported by public funding and universal access, simply entrench individuals in a system of self-surveillance. ${ }^{27}$ These individuals are then charged with the task of eliminating or at the very least avoiding harmful risks posed to future children. Abby Lippman has described this emphasis on individual risk management as having the effect of converting the 'at-risk' category into a disease state while framing 'natural experiences as causes of future diseases'. ${ }^{28}$

One example of this kind of individualisation of risk can be seen in the work of bioethicists Pieter Bonte et al documenting what they call the Preconception care (PCC) armoury. They have collated this armoury from a number of sources, but principally the Health Council of the Netherlands's Preconception Care: a Good Beginning. ${ }^{29}$ The armoury consists of nine obligations which the authors do not endorse in their entirety but describe as offering an idea of 'the demands a fully-fledged PCC regime would put on potential parents' ${ }^{30}$ Obligations 5, 6 and 8 on the list represent particularly notable instances of neoliberal burden shifting away from the State to the individual and I will address obligations 5 and 6 below and obligation 8 under the heading 'Universal screening and the impact on the reproductive rights of people with disability and people who test positive for carrier status' below.

Obligation 5 suggests that individuals should take care to avoid environmental toxins. Undertaking work with particular kinds of hazardous chemicals is clearly ill advised prior to conceiving for both men and women and when a woman is pregnant. ${ }^{31}$ However, even

\footnotetext{
${ }^{25}$ Royal Australian and New Zealand College of Gynaecologists and Human Genetics Society of Australasia (2015), p 14.

${ }^{26}$ Delatycki et al (2014), p 583.

${ }^{27}$ For a detailed discussion of different government preconception health care initiatives see: Karpin (2010).

${ }^{28}$ Lippman (2006).

${ }^{29}$ Health Council of the Netherlands (2007).

${ }^{30}$ Bonte et al (2014). The list includes: (1) follow a number of specific dietary prescriptions; (2) take specific supplements; (3) avoid obesity and anorexia; (4) moderate or abstain from use of alcohol, tobacco and various other recreational drugs; (5) avoid specific environmental exposures and chemicals; (6) avoid excessive psychological stress; (7) take specific precautionary measures in case of maternal health problems or when taking medication prior to conception; (8) avoid consanguinity and (in case of suspected risk) undergo genetic screening and if necessary, take appropriate measures, such as using assisted reproduction techniques, choosing a different reproductive partner, or abstaining from reproduction; and (9) last but not least time conception at an 'optimal age' via contraception and other means of family planning.

${ }^{31}$ Indeed in the now well-known 1991 case of United Auto Workers v Johnson Controls US 111 S Ct 1196 (1991), the United States Supreme Court found that Johnson Controls attempts to stop fertile women working in jobs involving exposure to high levels of lead were in contravention of the anti-discrimination provisions in Title VI. One of the reasons this was found to be discriminatory was that it could not be shown that men were not also similarly affected. Women fought for the right to be exposed because these were some of the best paying jobs and ones with real promotional opportunities.
} 
if it were possible to avoid work involving exposure to high levels of toxins, simply placing the burden of avoiding environmental exposures on the individual woman who may become pregnant is misguided. Toxins that may impact yet-to-be-born children exist in homes as well as workplaces and the broader environment. It is simply not feasible, as an individual, to purify one's environment of all potential toxicity. Alana Cattapan et al predict that this kind of burden shifting will mean:

Women who fail to avoid cosmetics laden with phthalates, or who buy a used sofa leaching flame retardants, may one day be seen as negligent by failing to avoid known toxic substances... ${ }^{32}$

Obligation 6 of the PCC armoury list urges us to avoid excessive psychological stress. Arguably, this is more absurd than avoiding ubiquitous chemical toxins. It is tempting to think that with the appropriate combination of therapy, anti-depressants and exercise the individual can manage themselves into a state of well-being. However, even if we were able to control our own levels of stress, recent research in the field of epigenetics suggests stress and trauma may have already left its intergenerational mark on our children's future well-being in the generation of our children's grandparents. ${ }^{33}$ The mechanism for transmission is not DNA mutations - for which we might screen - but rather occurs through the regulation of gene expression, that is, epigenetically.

If we decide to provide universal publicly funded genetic testing the testing burden created by expanded carrier screening must be weighed against other public health initiatives that might be activated to avoid future harm. Miranda Waggoner and Tobias Uller describe epigenetics as 'the study of how environmental exposures (including those internal to the organism) alter gene activity without changing the genetic makeup of the individual'. ${ }^{34}$ The most commonly discussed epigenetic mechanism is DNA methylation, which has as one of its functions modification of gene expression. ${ }^{35}$ Exposure to environmental stress or trauma in one generation may, it is claimed, cause a gene to turn on or turn off in the next generation or even across several generations. These are heritable changes in gene expression - rather than changes to the gene or DNA itself. What is interesting about this new research is that it suggests that genetic testing may be ineffective. Instead disparities in health that appear across generations may derive from environmental and social forces. Bridget Goosby and Chelsea Heidbring for instance argue that:

The health consequences of racism and discrimination can be persistent and passed from one generation to the next through the body's 'biological memory' of harmful experiences. ${ }^{36}$

The expectation of individual action via expanded carrier testing to avoid what are claimed to be harmful reproductive outcomes (and I will return to the question of what constitutes a harm below) thus bumps up against the problem that genes do not determine health and well-being and that health and well-being are not uncontroversial normative standards.

\footnotetext{
${ }^{32}$ Cattapan et al (2015), p 110.

${ }^{33}$ Warin et al (2015), Meloni (2015), Landecker and Panofsky (2013), Sullivan (2013), Geronimus (2013), Rutter (2012) and Rothstein et al (2009).

${ }^{34}$ Waggoner and Uller (2015), p 177.

${ }^{35}$ Waggoner and Uller (2015), p 179.

${ }^{36}$ Goosby and Heidbring (2013).
} 


\section{What constitutes a normatively undesirable genetic profile and the ethical implications for a progressive and inclusive approach to people with disability?}

As indicated above, expanded carrier testing raises real questions about how we conceptualise the normal genome and a healthy future. According to Sara Wienke et al, ' $\mathrm{i}] \mathrm{t}$ is estimated that each individual is a carrier of between zero and seven severe childhood recessive conditions with an average of 2.8 found in one study, ${ }^{37}$ This has led authors such as Michelle McGowan et al to suggest that ' $\mathrm{t}]$ he inclusion of more disease risks in [carrier screening] panels brings with it the increased possibility that more pregnant women will receive positive results, potentially making identification as a carrier "the new normal"'. 38 Therefore, it is no small concession to require - as the ACOG and ACMG Joint Statement does - that screening be restricted to variants 'with the highest likelihood of being pathogenic'. ${ }^{39}$

That being the case, it is clear that a careful approach must be adopted to any move towards universal publicly funded carrier screening. It must be tempered by a well-defined understanding of how variants are identified as sufficiently severe to warrant avoidance strategies, and who is placed to decide. With an expanding array of testing capabilities, it becomes increasingly difficult to determine whether the test proposed will identify a variation that is scientifically insignificant, or a variation that results in the birth of child with a severe disability.

Disability is both a broad term and a controversial one. In the context of preconception genetic testing, and universal publicly funded access thereto, the question of what kinds of differences might make up the category of normatively undesirable disability should form a large component of the discussion. This requires a deep attention to critical disability studies critiques that challenge presumptive appeals to the self-evidence of a harmful outcome. Jackie Leach Scully sums it up well when she says that 'an all-embracing category of "disability" ... homogenizes the enormous range of manifestations and aetiologies of disability $\ldots{ }^{40}$ In the preconception context where the risk of passing on a genetic anomaly is seen as a key concern, there is, as Scully goes on to note, a tendency 'especially in the popular media, to support a vastly oversimplified picture in which all genotypic or phenotypic variation is an adverse deviation from the norm'. ${ }^{41}$ As stated at the outset what constitutes the norm is determined by the social as well as scientific context and may rely on unstated assumptions about what it is to be healthy. Feminist and critical race studies critiques show, for example, how the idea of 'health' itself may be gendered and raced. ${ }^{42}$ For example, recent work examining the higher incidence of autism spectrum disorder (ASD) in boys has revealed that this may be due to a gender bias in the diagnosis and characterisation of the disorder. ${ }^{43}$ Importantly, although there is no genetic marker for ASD, there has been considerable research effort and money invested in trying to identify

\footnotetext{
${ }^{37}$ Wienke et al (2014), p 191.

${ }^{38}$ McGowan et al (2013), p 9.

${ }^{39}$ Edwards et al (2015), p 7.

${ }^{40}$ Scully (2008), p 800.

${ }^{41}$ Scully (2008), p 800.

${ }^{42}$ Tang et al (2008), Gough (2006), Johnson et al (2004), Tolman et al (2003) and Courtenay (2000).

${ }^{43}$ Constantino and Charman (2012), Gillis-Buck and Richardson (2014), Goldman (2013) and Bombaci (2012), p 144.
} 
one. ${ }^{44}$ Yet clearly a condition that exists along a spectrum and that has, as one of its distinguishing characteristics, 'deficits in social communication', ${ }^{45}$ requires a complex and nuanced approach to disability that recognises it is both created out of as well as in its social context. It is clear then that any policy aimed at providing universal and publicly funded access to genetic screening must also entrench a nuanced and complex approach to disability that protects individuals from discrimination who may not share normative views about whether a particular disability is so undesirable as to warrant genetic screening. Kyle Anstey argues, for instance, that traits associated with disability 'demand examination in the varied context of both parental lifeplans and personal and socioenvironmental barriers to, and facilitators of, functioning. ${ }^{46}$

What constitutes a genetic abnormality for which screening or testing is warranted is laden with contextually driven values and ideas about what it is to be healthy and well. Indeed as I have argued elsewhere (with Karen O'Connell) '[d]isability itself is a controversial idea and inflected and distorted by associated levels of stigmatisation'. ${ }^{47}$

Nevertheless, arguably the availability and accessibility of preconception genetic carrier screening is something that can be controlled and offered equitably. A number of professional bodies and public health organisations have gone so far as to recommend whole-population carrier screening for preconception purposes as a matter of health equity. ${ }^{48}$ However, as has just been shown what counts as a screenable genetic anomaly cannot simply be aligned with a negative phenotypic outcome. The meaning to be derived from the existence of a specific gene will vary depending on the context and views in that context about what constitutes a disability.

\section{Universal screening and the impact on the reproductive rights of people with disability and people who test positive for carrier status}

Obligation 8 on Bonte et al's PCC armoury list, which, amongst other things, suggests that prospective parents 'undergo genetic screening and if necessary, take appropriate measures such as using assisted reproduction techniques, choosing a different reproductive partner, or abstaining from reproduction ${ }^{39}$ indicates a clear expectation that prospective parents will access preconception screening. There is a growing expectation in places like Australia and other developed nations that potential parents engage in some level of preconception genetic self-surveillance. Bonte et al suggest that:

A normal and reasonably prudent prospective parent ... who has good reason to assume that he/she belongs to a group with an elevated genetic risk of severely afflicting future offspring, would be acting morally irresponsibly if he/she knowingly foregoes genetic carrier screening. ${ }^{50}$

Given that it is unlikely a person will have 'good reason to assume' they belong to an atrisk group unless they themselves or someone closely related has a disability, the

\footnotetext{
${ }^{44}$ Yuen et al (2015), Herbert et al (2006) and Risch et al (1999).

${ }^{45}$ Autism Speaks (date unknown).

${ }^{46}$ Anstey (2008), p 246.

${ }^{47}$ Karpin and O'Connell (2015).

${ }^{48}$ Human Genetics Commission UK (2011).

${ }^{49}$ Bonte et al (2014).

${ }^{50}$ Bonte et al (2014).
} 
admonition against morally irresponsible behaviour immediately singles out prospective parents who themselves have a serious inheritable condition or who are closely related to someone who does. However, there is no consensus about what constitutes a serious disability. While it might be possible to identify a gene with a particular phenotypic outcome, the significance of the phenotype depends in large measure on the social context in which the individual will be living. Disabilities that manifest in challenging behaviour are a perfect example of this. Research that is currently being undertaken to identify the genetic origins of traits such as aggression, lack of empathy and anti-social behaviour ${ }^{51}$ relies on a shared consensus about what is pro-social behaviour. As I have argued elsewhere (with O'Connell) ' $t$ ] his means that the type of society in which one is born, or the type of public sphere one wants to inhabit, determines whether a person will be diagnosed with a medical "disorder" associated with challenging behaviour. ${ }^{52}$ If we perceive disability simply as a medical condition then the idea of repair is limited to medical care of the individual whether that be through genetic testing technologies or gene therapy or whatever else is on the horizon. However, if we understand disability as constituted by the social context, amongst other things, then our responses will be contingent on what kind of disability/ ability is valued in that context. Indeed, it has been established through the work of Sol Levine, Gary Albrecht and others, that the concept of disability and its various qualifiers - serious, severe, life threatening - requires interpretation in a social context. These authors have found that a disability paradox exists whereby those who have what are understood to be disabling traits view their quality of life in far more positive terms than those who do not. ${ }^{53}$ This includes not just the public generally but also health care workers who might be thought to have a more complex understanding. Furthermore, while an individual may have a genetic condition that has a variable presentation from mild to severe, under Bonte et al's prudential thinking, such a person would be expected to test to exclude their condition just in case their offspring are born with a more severe version. In other words, while this statement reads rather neutrally - directed at all people of varying ability and both men and women - in fact it has a much greater impact on members of a narrow population who it implies do not have the right to view their reproductive life plans normatively. Instead they must view them with suspicion and take risk avoidance strategies if they are to be viewed as moral beings.

\section{Conclusion: What would universal publicly funded equality of access to expanded carrier screening entail?}

At the present time, unlike PGD, in Australia and across the State jurisdictions there is very little formal legislative control of preconception genetic testing or expanded carrier testing. Most regulation occurs in the form of professional guidelines and government health department policy documents. Genetic information, with its capacity to reveal the health status of both individuals and their kin, as well as being predictive of potential future health developments, makes people vulnerable to discrimination. Were expanded carrier testing to be made universally accessible and publicly funded, it would need to be coupled with protective

\footnotetext{
${ }^{51}$ Elev et al (2003), Beaver et al (2008) and Viding et al (2005).

${ }^{52}$ Karpin and O'Connell (2015).

${ }^{53}$ See, for example, Albrecht and Devlieger (1999) and Levine (1987).
} 
legislation. Even if it were carefully regulated so that it was limited to an agreed set of conditions that required a threshold of severity, penetrance and age of onset, people who were revealed to carry genetic anomalies would need to be protected from discrimination. They would need to be protected from discrimination on the basis of their genetic status (in access to insurance, employment, education and other goods and services) but, perhaps more importantly, in terms of their right to reproduce unmolested by a genetic testing imperative.

It is important that if we move towards making genetic screening universally accessible and publicly funded we do not, at the same time, preclude individuals who test positive as carriers from reproducing using their own genetic material if they so wish. As we have already seen, some forms of genetic testing may be activated along racial lines and, in the case of tests that reveal the presence of genes such as BRCA1 and BRCA2 (the so-called breast cancer gene) there is a significant potential for a gendered approach to testing as well. ${ }^{54}$ This kind of intersectional dimension must also be addressed in any access and protection regime.

Genetic discrimination is already indirectly covered by Australia's federal and state systems of anti-discrimination laws, primarily by the Disability Discrimination Act 1992 (Cth) (DDA). The DDA applies to disabilities 'imputed to a person' in s 4 and was amended in 2009, so that it also applies to disabilities that may exist in the future including because of a genetic predisposition to that disability'. This protection from discrimination applies to education, employment and goods and services. There are some examples of genetic discrimination complaints in Australia such as denial of life insurance due to the presence of the MSH6 gene, which increases susceptibility for colon cancer; ${ }^{55}$ however, there have not yet been any reported court cases on genetic discrimination in Australia. ${ }^{56}$ Because of this it is difficult to know whether discrimination on the grounds of carrier status would be caught by this definition. Carrier status might be described quite differently since the person is not themselves disabled, will not become disabled in the future and the disability is not imputed to them but rather to their future children. It is quite possible, however, that people will be stopped or at least discouraged and counseled against using their own gametes in this situation. In these circumstances they are not exactly being discriminated against on the grounds of their own disability unless carrier status itself can be characterised as a disability, raising further concerns.

In other jurisdictions, genetic discrimination is regulated more directly. In the United States, the Genetic Information Non Discrimination Act (GINA) makes genetic discrimination unlawful in insurance and education. ${ }^{57}$ Genetic information in this context includes an individual's predisposition towards a condition, but more importantly for the preconception context, it extends to include a prohibition on the use of family health history. ${ }^{58}$ While the same limit extends to employers it does not, however, include life insurance or access to goods and services generally. This means that this provision will

\footnotetext{
${ }^{54}$ It should be noted that the proposal by the ACOG Joint Statement that age of onset would be a factor to be considered in any testing protocol might mean that BRCA 1 and 2 would not be included in universal panel testing. Notably, however, PGD is available in Australia to test for the presence of these breast cancer genes in embryos. See, for example, the website of IVF Australia which boasts PGD for BRCA1 and 2, http://ivf.com.au/fertility-treatment/genetic-testingpgd\#what-single-gene-disorders-can-pgd-test-for-.

${ }^{55}$ Keogh and Otlowski (2013).

${ }^{56}$ In the US, see Burlington Northern and Santa Fe Railway Company v Sheila White 126 S. Ct. 2405 (2006).

${ }^{57}$ Genetic Information and Non Discrimination Act (GINA) Pub.L. No, 110-233, 122 Stat. 881 (2008).

${ }^{58}$ GINA s 102(a).
} 
not protect individuals' denied access to Assisted Reproductive Technology (ART) services on the basis of their carrier status. In that case they would need to rely on other protections such as those that exist under the Americans with Disabilities Act 1990 (ADA). The definition of disability found in the ADA would capture individuals' refused access to ART due to a disability; however, it is not clear that carrier status would be captured. On top of this there is significant case law showing that many prospective parents who have an existing disability are denied access to these services in flagrant disregard for the Act. ${ }^{59}$ In the UK, genetic discrimination has not been directly prohibited and there is concern raised that new expanded carrier testing will 'provide a platform for genetic testing to be used for novel and unpredicted purposes'. ${ }^{60}$ There was a suggestion that the UK Equality Act 2012 be extended to cover genetic discrimination; however, that has not happened. Furthermore, the definition of disability in the Equality Act 2012 is even more circumscribed than in either the DDA or the ADA. Thus again a question arises about whether it extends to cover someone who is not disabled but is a carrier of a condition.

Comprehensive regulations outlawing genetic discrimination in access to ART services, amongst other things, may therefore be a necessary first step in the development of a manageable regime of publicly funded universal and expanded carrier testing. However, even in the presence of protective legislation, subtle forms of pressure can be applied to discourage people who test positive from reproducing without utilising disability avoidance strategies. Any move towards equal access to publicly funded universal preconception genetic testing must include a careful strategy for ensuring that ideas of normalcy and disability are always up for discussion and for ensuring that those individuals who choose to reproduce using their own gametes despite the presence of a genetic 'abnormality' continue to be able to do so in the same way as people who do not have such a condition.

\section{Acknowledgements}

Thank you to Valerie Gutenev-Hale for her research assistance, Karen O'Connell and David Ellison for their helpful comments and the useful suggestions of the anonymous reviewers.

\section{Disclosure statement}

No potential conflict of interest was reported by the author.

\section{Funding}

This research is supported by Australian Research Council [grant number DP150102935] "The Legal Regulation of Behaviour as a Disability" 2015-18 (with Dr Karen O’Connell).

\section{ORCID}

Isabel Ann Karpin (D) http://orcid.org/0000-0001-9326-3421

\footnotetext{
${ }^{59}$ National Council on Disability (2012).

${ }^{60}$ Human Genetics Commission (2011).
} 


\section{References}

\section{Primary Sources}

Caselaw

Burlington Northern and Santa Fe Railway Company v Sheila White 126 S. Ct. 2405 (2006)

Legislation

Americans with Disabilities Act 1990.

Disability Discrimination Act 1992 (Cth).

Equality Act 2012 (UK).

Genetic Information and Non Discrimination Act (GINA) Pub.L. No, 110-233, 122 Stat. 881 (2008).

\section{Secondary Sources}

Gary Albrecht and Patrick Devlieger (1999) 'The Disability Paradox: High Quality of Life Against all Odds' 48 Social Science and Medicine 977.

American College of Obstetricians and Gynecologists Committee on Genetics ACOG (2011) 'Committee Opinion No. 486: Update on Carrier Screening for Cystic Fibrosis' 117 Obstetrics and Gynecology 1028.

Kyle Anstey (2008) 'A Critique of Arguments Supporting Disability Avoidance' 23(2) Disability and Society 235.

Adrienne Asch (2003) 'Disability Equality and Prenatal Testing: Contradictory or Compatible?' 30 Florida State University Law Review 315.

Autism Speaks (date unknown) 'What is Autism - DSM-5 DiagnosticCriteria' http://www. autismspeaks.org/what-autism/diagnosis/dsm-5-diagnostic-criteria.

Komal Bajaj and Susan Gross (2014) 'Carrier Screening: Past, Present and Future' 3(3) Journal of Clinical Medicine 1033.

Kevin Beaver et al (2008) 'The Intersection of Genes and Neuropsychological Deficits in the Prediction of Adolescent Delinquency and Low Self-Control' 54(1) International Journal of Offender Therapy and Comparative Criminology 22.

Maria Berghs et al (2015) 'Resignifying the Sickle Cell Gene: Narratives of Genetic Risk, Impairment and Repair' Health 1. doi:10.1177/1363459315595850

Nancy Bombaci (2012) 'Popular Discourses on the Neurotypical Woman: Conformity, Authority and Post-War Femininities' 23(2) Women: A Cultural Review 139, 144.

Pieter Bonte et al (2014) 'Is There a Moral Obligation to Conceive Children under the Best Possible Conditions? A Preliminary Framework for Identifying the Preconception Responsibilities of Potential Parents' 15(5) BMC Medical Ethics 2.

Alana Cattapan et al (2015). 'Notions of Reproductive Harm in Canadian Law: Addressing Exposures to Household Chemicals as Reproductive Tools' 1 CJCCL 79.

John Constantino and Tony Charman (2012) 'Gender Bias, Female Resilience, and the Sex Ratio in Autism' 51(8) Journal of the American Academy of Child and Adolescent Psychiatry 756.

Will Courtenay (2000) 'Constructions of Masculinity and Their Influence on Men's Well-Being: A Theory of Gender and Health' 50(10) Social Science \& Medicine 1385.

Martin Delatycki et al (2014) 'Human Genetics Society of Australasia Position Statement: Population-based Carrier Screening for Cystic Fibrosis' 17(6) Twin Research and Human Genetics 578.

Janice Edwards et al (2015) 'Expanded Carrier Screening in Reproductive Medicine-Points to Consider: A Joint Statement of the American College of Medical Genetics and Genomics, American College of Obstetricians and Gynecologists, National Society of Genetic Counselors, Perinatal Quality Foundation, and Society for Maternal-Fetal Medicine' 125(3) Obstetrics \& Gynecology 653.

Thalia Elev et al (2003) 'A Longitudinal Behavioral Genetic Analysis of the Etiology of Aggressive and Nonaggressive Antisocial Behavior' 15(2) Development and Psychopathology 383.

Elizabeth Ettorre (2002) Reproductive Genetics, Gender and the Body, Routledge.

Arline Geronimus (2013) 'Deep Integration: Letting the Epigenome Out of the Bottle Without Losing Sight of the Structural Origins of Population Health' 103(S1) American Journal of Public Health S56. 
Eva Gillis-Buck and Sarah Richardson (2014) 'Autism as a Biomedical Platform for Sex Differences Research' 9 BioSocieties 262.

Sylvie Goldman (2013) 'Opinion: Sex, Gender and the Diagnosis of Autism - A Biosocial View of the Male Preponderance’ 7(6) Research in Autism Spectrum Disorders 675.

Bridget Goosby and Chelsea Heidbring (2013) 'The Transgenerational Consequences of Discrimination on African-American Health Outcomes' 7(8) Sociology Compass 630.

Brendan Gough (2006) 'Try to Be Healthy, But Don't Forgo Your Masculinity: Deconstructing Men's Health Discourse in the Media' 63(9) Social Science \& Medicine 2476.

Health Council of the Netherlands (2007) 'Preconception Care: A Good Beginning' http://www. gezondheidsraad.nl/sites/default/files/200719e.pdf

MR Herbert et al (2006) 'Autism and Environmental Genomics' 27 NeuroToxicology 671.

Human Genetics Commission UK (2011) 'Increasing Options, Informing Choice: A Report on Preconception Genetic Testing and Screening' http://f.hypotheses.org/wp-content/blogs.dir/ 257/files/2011/04/2011.HGC_.-Increasing-options-informing-choice-final2.pdf.

Julia Inthorn (2014) 'Fuzzy Logic and Preconceptional Genetic Carrier Screening' 1 Archives for the Philosophy and History of Soft Computing 5.

Joy Johnson et al (2004) 'Othering and Being Othered in the Context of Health Care Services' 16(2) Health Communication 255.

Isabel Karpin (2010) 'Taking Care of the Health of the Preconceived Embryos or Constructing Legal Harm' in J Nisker, F Baylis, I Karpin, C McLeod \& R Mykitiuk (eds), The Healthy Embryo, Cambridge University Press, pp. 136-150.

Isabel Karpin and Karen O'Connell (2015) 'Stigmatising the Normal: The Regulation of Behavior as a Disability' 38(4) University of New South Wales Law Journal 9.

Isabel Karpin and Kristin Savell (2012) Perfecting Pregnancy: Law Disability and the Future of Reproduction, Cambridge University Press.

Louise Keogh and Margaret Otlowski (2013) 'Life Insurance and Genetic Test Results: A Mutation Carrier's Fight to Achieve Full Cover' 199(5) The Medical Journal of Australia 363.

Hannah Landecker and Aaron Panofsky (2013) 'From Social Structure to Gene Regulation, and Back: A Critical Introduction to Environmental Epigenetics for Sociology' 39 Annual Review of Sociology 333.

Sol Levine (1987) 'The Changing Terrains in Medical Sociology: Emergent Concern with Quality of Life' 28 Journal of Health and Social Behavior 1.

Raelia M. Lew et al (2015) 'Tay-Sachs Disease: Current Perspectives from Australia' 8 The Application of Clinical Genetics 19.

Abby Lippman (1991) 'Prenatal Genetic Testing and Screening: Constructing Needs and Reinforcing Inequities' 17(1-2) American Journal of Law and Medicine 15.

Abby Lippman (2006) 'The Inclusion of Women in Clinical Trials: Are We Asking the Right Questions?' http://www.whp-apsf.ca/pdf/clinicalTrialsEN.pdf.

Michelle McGowan et al (2013) 'The Changing Landscape of Carrier Screening: Expanding Technology and Options?' 23(1) Health Matrix Clevel 15.

Maurizio Meloni (2015) 'Heredity 2.0: The Epigenetics Effect' 34(2) New Genetics and Society 117. Lucy Modra et al (2010) 'Ethical Considerations in Choosing a Model for Population-based Cystic Fibrosis Carrier Screening' 193(3) Medical Journal of Australia 157.

National Council on Disability (2012) 'Rocking the Cradle: Ensuring the Rights of Parents with Disabilities and Their Children Chapter 11' https://www.ncd.gov/publications/2012/ Sep272012/Ch11.

Erik Parens and Adrienne Asch (2003) 'Disability Rights Critique of Prenatal Genetic Testing: Reflections and Recommendations' 9 Mental Retardations and Developmental Disabilities Research Reviews 40.

Jo C. Phelan et al (2013) 'The Genomic Revolution and Beliefs about Essential Racial Differences: A Backdoor to Eugenics?' 78(2) American Sociological Review 167.

Neil Risch et al (1999) 'A Genomic Screen of Autism: Evidence for a Multilocus Etiology' 65(2) The American Journal of Human Genetics 493. 
Mark Rothstein et al (2009) 'The Ghost in Our Genes: Legal and Ethical Implications of Epigenetics' 19(1) Health matrix 1.

Royal Australian and New Zealand College of Gynaecologists and Human Genetics Society of Australasia (2015) 'Prenatal Screening and Diagnosis of Chromosomal and Genetic Abnormalities in the Fetus in Pregnancy: C-Obs 59'.

Michael Rutter (2012) 'Gene-Environment Interdependence' 9(4) European Journal of Developmental Psychology 391.

Rosamund Scott (2007) Choosing Between Possible Lives: Law and Ethics of Prenatal and Preimplantation Genetic Diagnosis, Hart Publishing.

Jackie Leach Scully (2008) 'Disability and Genetics in the Era of Genomic Medicine' 9 Nature Reviews Genetics 797.

Shannon Sullivan (2013) 'Inheriting Racist Disparities in Health: Epigenetics and the Transgenerational Effects of White Racism' 1(2) Critical Philosophy of Race 190.

Sannie Tang et al (2008) 'Race' Matters: Racialization and Egalitarian Discourses Involving Aboriginal People in the Canadian Health Care Context' 13(2) Ethnicity and Health 109.

Deborah Tolman et al (2003) 'Gender Matters: Constructing a Model of Adolescent Sexual Health' 40(1) Journal of Sex Research 4.

Essi Viding et al (2005) 'Evidence for Substantial Genetic Risk for Psychopathy in 7-Year-Olds' 46 (6) Journal of Child Psychology and Psychiatry 592.

Miranda R Waggoner and Tobias Uller (2015) 'Epigenetic Determinism in Science and Society' 34 (2) New Genetics and Society 177.

Megan Warin et al (2015) 'Epigenetics and Obesity the Reproduction of Habitus Through Intracellular and Social Environments' Body \& Society. doi:10.1177/1357034X15590485.

Sara Wienke et al (2014) 'Expanded Carrier Screening Panels - Does Bigger Mean Better?' 5 Journal of Community Genetics 191.

Ryan Yuen et al (2015) 'Whole-genome Sequencing of Quartet Families with Autism Spectrum Disorder’ 21(2) Nature Medicine 185. 